\title{
Oligosaccharides and glycoconjugates in bovine milk and colostrum
}

\author{
Pramod K. Gopal ${ }^{1}$ and H. S. Gill ${ }^{1,2}$ \\ ${ }^{1}$ New Zealand Dairy Research Institute, Massey University, Palmerston North, New Zealand \\ ${ }^{2}$ Milk and Health Research Centre, Massey University, Palmerston North, New Zealand
}

\begin{abstract}
Oligosaccharides and glycoconjugates are some of the most important bioactive components in milk. A great deal of information is available on the biological function of the components from human milk. Their primary role seems to be in providing protection against pathogens by acting as competitive inhibitors for the binding sites on the epithelial surfaces of the intestine. Evidence is also available to support the role of some of these components as growth promoters for genera of beneficial microflora in the colon. Compared with human milk, levels of oligosaccharides in bovine milk are very low. Nevertheless, a number of neutral and acidic oligosaccharides have been isolated from bovine milk and characterised. The highest concentration of these molecules is found in early postparturition milk (colostrum). The chemical structure of the oligosaccharides and many of the glycoconjugates from bovine milk are similar to those in human milk. It is likely that bovine oligosaccharides and glycoconjugates can be used in milk products as bioactive components in human nutrition.
\end{abstract}

Oligosaccharides: Glycoconjugates: Bovine milk: Colostrum

\section{Introduction}

Milk is nature's designer food to fulfil the nutritional needs for the growth and development of the neonate. The composition of milk progressively changes postparturition to meet the changing and specific requirements of the suckling neonate. During the first few days postparturition, the 'early milk' (colostrum) has a composition quite different from that of 'mature' milk. In the case of bovine milk, the first four days of milk postparturition constitute colostrum. In addition to normal nutrients such as proteins, carbohydrates, fats, vitamins and minerals, colostrum contains many other biologically active constituents. These include growth factors, antimicrobial compounds and immune-enhancing components. The role of milk in these first few days in the life of a newborn calf is not only to provide nutrition, but also to provide protection against infection while the immune system is still developing.

In addition to lactose, the carbohydrate or carbohydratecontaining components of bovine milk and colostrum include oligosaccharides, glycoproteins and glycolipids. In this review we focus on the composition, chemical structure and physiological role of these carbohydrate-rich components. We also explore the role of these compounds as micronutrients in human nutrition, especially with regard to their potential health benefits.

\section{General composition of bovine and human milk and colostrum}

The composition of bovine milk and colostrum, in terms of the major nutritional components, are summarised in Table 1. In comparison with milk, it is difficult to assume a 'typical' composition profile for bovine colostrum. The composition and physical characters vary greatly with individual breeds, feeding, length of dry period of cows and time postparturition. A notable difference between bovine milk or colostrum and their human counterparts is their oligosaccharide content.

\section{Oligosaccharides in bovine colostrum and milk}

Oligosaccharides are strictly defined as carbohydrates which contain between three and ten monosaccharide residues covalently linked through glycosidic bonds. However, disaccharides (which contain only two residues) other than lactose are often also designated as oligosaccharides. Oligosaccharides are divided into two broad classes, neutral and acidic. Neutral oligosaccharides do not contain any charged carbohydrate residues. However, acidic oligosaccharides contain one or more residues of $\mathrm{N}$-acetylneuraminic acid (sialic acid) which are negatively charged (hence the term acidic).

\footnotetext{
* Corresponding author: Dr P. K. Gopal, fax +64 6354 1756, email pramod.gopal@nzdri.org.nz
} 
Table 1. Composition of bovine and human milk and colostrum (g/100 ml)

\begin{tabular}{|c|c|c|c|c|c|}
\hline & Protein & Lactose & Oligosaccharides & Fat & Ash \\
\hline Bovine milk* & 3.4 & $4 \cdot 6$ & $\ddagger$ & 3.7 & 0.7 \\
\hline Bovine colostrum† & $4 \cdot 1-14 \cdot 0$ & $2 \cdot 7-4 \cdot 6$ & $\ddagger$ & $3 \cdot 9-4 \cdot 4$ & $0.5-2$ \\
\hline Human milk§ & $1 \cdot 0$ & $6 \cdot 8$ & $1 \cdot 3$ & 3.9 & 0.2 \\
\hline Human colostrum§ & 1.0 & $5 \cdot 5$ & $2 \cdot 4$ & 3.0 & - \\
\hline
\end{tabular}

It was recognised as early as 1933 that human milk contained a major carbohydrate component which was not lactose (Polonosky \& Lespagnol, 1933). At the time, the component was termed gynolactose, but it is now known that this fraction consists mainly of oligosaccharides. In human milk, oligosaccharides are the third major component, present at a higher concentration (on a weight per volume basis) than total protein (Table 1). With advances in analytical techniques, approximately 80 acidic and neutral oligosaccharides have been isolated from human milk and their chemical structures have been determined (Newberg \& Neubauer, 1995).

In comparison to human breast milk, the oligosaccharide composition of bovine milk is simple: ten sialyl oligosaccharides (Table 3) and eight neutral oligosaccharides (Table 2) have been described in bovine milk and colostrum.

\section{Neutral oligosaccharides}

The first report on neutral oligosaccharides from bovine milk or colostrum appeared in 1984. Saito et al. (1984) described the chemical structure of two neutral disaccharides in colostrum collected $6 \mathrm{~h}$ postparturition from Holstein-Friesian cows. These two disaccharides accounted for $74 \%$ of the neutral oligosaccharide fraction (excluding lactose). $\mathrm{N}$-Acetyl-lactosamine was by far the major component, accounting for $70 \%$.

Using liquid chromatography on amino silica gel, Saito et al. (1987) isolated three neutral trisaccharides from bovine colostrum, one of which contained fucose. This was the first report describing a fucosylated oligosaccharide from bovine colostrum. Two further trisaccharides and a pentasaccharide from bovine colostrum were subsequently described by Urashima et al. (1991). The chemical structure of these molecules in bovine colostrum is summarised in Table 2. In all cases, early colostrum (i.e. colostrum collected within $6 \mathrm{~h}$ postparturition) was used in the studies. It has been reported that the oligosaccharide composition of colostrum changes rapidly postparturition, and Saito et al. (1984) showed that two key disaccharides present in early colostrum are completely absent 7 days after parturition.

\section{Acidic oligosaccharides}

Quantitatively, oligosaccharides are only present in bovine milk in trace amounts; considerably higher concentrations are present in bovine colostrum. As milk production matures postparturition, the concentration of these oligosaccharides declines rapidly. This makes isolation and analysis technically difficult.

The first report on sialyl oligosaccharides from bovine colostrum appeared in 1956 (Kuhn \& Brossmer, 1956). Ten years later, Schneir \& Rafelson (1966) devised a simpler procedure for extraction of larger quantities of sialyl oligosaccharides from bovine colostrum and reported the isolation of two isomers of $\mathrm{N}$-acetylneuraminyl-lactose. Further improvements in the methodology by Veh et al. (1981), and later Parkkinen \& Finne (1987), resulted in the discovery of a range of sialyl oligosaccharides from bovine colostrum.

Parkkinen \& Finne (1985) also demonstrated the presence of two phosphorylated sialyl oligosaccharides in bovine colostrum. One of these compounds was structurally similar to a previously characterised sialyl oligosaccharide found in human urine, namely sialyl-lactosamine-1-phosphate. The second sialyl oligosaccharide was completely novel and contained a phosphate group in position 6, i.e. sialyl-lactosamine-6-phosphate. In total, ten sialylated oligosaccharides have now been described from bovine colostrum. The chemical structures of these oligosaccharides are summarised in Table 3.

The most abundant acidic oligosaccharide reported in

Table 2. Neutral oligosaccharides of bovine milk and colostrum

\begin{tabular}{|c|c|c|}
\hline Structure & Name & Reference \\
\hline Gal $\beta(1-3)$ Gal $\beta(1-4)$ Glc & 3'-Galactosyl-lactose & Saito et al. 1987 \\
\hline Gal $\beta(1-6)$ Gal $\beta(1-4)$ Glc & 6'-Galactosyl-lactose & Saito et al. 1987 \\
\hline Gal- $\beta(1-4)$ Fuc $\alpha(1-3)$ GlcNAc & 3-Fucosyl $N$-acetyl-lactosamine & Saito et al. 1987 \\
\hline Gal $\beta(1-4)$ GlcNAc & $\mathrm{N}$-Acetyl-lactosamine & Saito et al. 1984 \\
\hline Gal $N A c \beta(1-4)$ Glc & $\mathrm{N}$-Acetylgalactosaminyl glucose & Saito et al. 1984 \\
\hline GalNAc $\alpha(1-3)$ Gal & $\mathrm{N}$-Acetylgalactosyl-lactose & Urashima et al. 1991 \\
\hline Gal $\beta(1-4)$ GlcNAc $\beta(1-6)$ Gal $\beta(1-3)[\mathrm{Gal} \beta(1-4) \mathrm{Glc}]$ & Lacto- $N$-novopentaose & Urashima et al. 1991 \\
\hline Gal $\alpha(1-3)$ Gal $\beta(1-4)$ Glc & $\alpha-3^{\prime}$-Galactosyl lactose & Urashima et al. 1991 \\
\hline
\end{tabular}


Table 3. Acidic oligosaccharides of bovine milk and colostrum

\begin{tabular}{lll}
\hline Structure & \multicolumn{1}{c}{ Name } & Reference \\
\hline NeuAc $\alpha(2-3)$ Gal $\beta(1-4)$ Glc & 3-Sialyl-lactose & Schneir \& Rafelson, 1966 \\
NeuAc $\alpha(2-6)$ Gal $\beta(1-4)$ Glc & 6-Sialyl-lactose & Schneir \& Rafelson, 1966 \\
NeuGl $\alpha(2-6)$ Gal $\beta(1-4)$ Glc & 6-Glucolylneuraminyl-lactose & Veh al. 1981 \\
NeuAc $\alpha(2-6)$ Gal $\beta(1-4)$ GlcNAc & 6-Sialyl-lactosamine & Veh et al. 1981 \\
NeuGl $\alpha(2-6)$ Gal $\beta(1-4)$ GlcNAc & 6-Glucolylneuraminyl-lactosamine & Veh et al. 1981 \\
NeuAc $\alpha(2-3)$ Gal $\beta(1-3)$ Gal- $\beta(1-4)$ Glc & 3-Sialyl galactosyl-lactose & Parkkinen \& Finne, 1987 \\
NeuAc $\alpha(2-8)$ NeuAc $\alpha(2-3)$ Gal $\beta(1-4)$ Glc & Disialyl lactose & Parkkinen \& Finne, 1987 \\
NeuAc $\alpha(2-6)$ Gal $\beta(1-4)$ GlcNAc $\alpha-1-P$ & Sialyl-lactosamine-1-phosphate & Parkkinen \& Finne, 1987 \\
NeuAc $\alpha(2-6)$ Gal $\beta(1-4)$ GlcNAc $\alpha-6-P$ & Sialyl-lactosamine-6-phosphate & Parkkinen \& Finne, 1987 \\
NeuGl $\alpha(2-3)$ Gal $\beta(1-4)$ Glc & 3-Glucolylneuraminyl-lactose & Veh et al. 1981 \\
\hline
\end{tabular}

bovine colostrum is 3-sialyl-lactose followed by sialyllactosamine, 6-sialyl-lactose and disialyl-lactose. Together, 3- and 6-sialyl-lactose account for more than $50 \%$ of the total oligosaccharides present in bovine colostrum. Interestingly, 3- and 6-sialyl-lactose are also major components of human milk and have been reported to reach concentrations of $1.0 \mathrm{~g} / \mathrm{l}$ (McVeagh \& Brand Miller, 1997). Table 4 compares the major oligosaccharides of human and bovine milks.

\section{Glycolipids, glycopeptides and glycoproteins from bovine milk}

In bovine milk, numerous complex carbohydrates are present as glyconjugates, i.e. the carbohydrate chains are attached covalently to the backbone of either proteins or lipids (Kobata, 1977). There has been significant interest in these molecules, especially in their potential value as micronutrients. For instance, infant formulas made with various bovine milk fractions have been assessed for their glycoconjugate content and with respect to benefits of complex carbohydrates for bottle-fed infants (Carlson, 1985; Cleary et al. 1985, Sanchez-Diaz et al. 1997). In a 1990 study, Neesser et al. used two fractionation procedures to quantitate gangliosides, neutral glycolipids and non-fat complex carbohydrates (glycoproteins and glycopeptides) from bovine milk and bovine milk-based infant formulas. This study concluded that most bovine milk-based infant formulas contained complex carbohydrates in amounts similar to those found in bovine milk. The main ganglioside in bovine milk is reported to be ganglioside containing two sailic acid residues (GD3) (Takamizawa et al. 1986).

Mucins are a family of glycoproteins which are heavily glycosylated. The first report on a mucin-like glycoprotein in bovine milk appeared in 1993, when Kanamaru et al. (1993) purified a high-molecular-weight glycoprotein from whey by gel-filtration. Similar high-molecular-weight mucin-like glycoproteins have been reported from human milk (Shimazu et al. 1986). The amino acid composition and lectin binding properties of the bovine mucin were found to be similar to the human counterpart. In human milk, the mucin-like glycoprotein has been shown to be part of the milk fat globular membrane (MFGM) and its function is believed to provide protection against protease degradation of the MFGM surface. Milk mucins, or their fragments, may also have a role in the inhibition of microbial infection. Schroten et al. (1992) demonstrated

Table 4. Major oligosaccharides of human milk and bovine colostrum*

\begin{tabular}{|c|c|c|c|}
\hline Oligosaccharide & Human milk† (g/l) & Bovine colostrum† (g/l) & Bovine colostrum $\ddagger(\mu \mathrm{mol} / \mathrm{l})$ \\
\hline Lactose & $55-70$ & $40-50$ & $27-46 \S$ \\
\hline Lacto- $N$-tetraose & $0.5-1.5$ & - & - \\
\hline Lacto- $N$-fucopentaose I & $1 \cdot 2-1 \cdot 7$ & - & - \\
\hline Lacto- $N$-fucopentaose II & $0.3-1.0$ & - & - \\
\hline Lacto- $N$-fucopentaose III & $0.01-0.2$ & - & - \\
\hline Lacto- $N$-difucohexaose & $0.1-0.2$ & - & - \\
\hline \multicolumn{4}{|l|}{ Acidic oligosaccharides } \\
\hline 6-Sialyl-lactose & $0.3-0.5$ & Trace & 30 \\
\hline 3-Sialyl-lactose & $0.1-0.3$ & Trace & 150 \\
\hline Sialyl-lacto- $N$-tetraose a & $0.03-0.2$ & & \\
\hline Sialyl-lacto- $N$-tetraose c & $0.1-0.6$ & & \\
\hline Sialyl-lactosamine & & Trace & 70 \\
\hline Sialyl galactosyl-lactose & & Trace & 3 \\
\hline Disialyl-lactose & & Trace & 30 \\
\hline Sialyl-lactose-1-phosphate & & Trace & 3 \\
\hline Sialyl-lactose-6-phosphate & & - & 1 \\
\hline 3-Glucolyl neuramyl-lactose & & - & 2 \\
\hline NeuAc2-lacto- $N$-tetraose & $0.2-0.6$ & - & - \\
\hline
\end{tabular}

* Table adapted from Kunz et al. (1999).

† Data taken from Montreuil \& Mullet (1960), and Kunz \& Rudloff (1993).

‡ Data from Parkkinen \& Finne (1987).

$\S \mathrm{g} / \mathrm{l}$. 
that milk mucin components interfere with the adhesion of Escherichia coli to epithelial cells of the buccal cavity. However, the exact biological significance of the mucinlike glycoprotein in bovine milk is not known.

\section{Physiological function and nutritional implications of oligosaccharides and glycoconjugates}

One theory on the physiological function of oligosaccharides in vivo is that they provide a low osmolar source of energy. This may be true in the case of animals where oligosaccharides are the predominant carbohydrate component of milk, and the gastrointestinal tract of that animal is equipped with appropriate enzymes to hydrolyse and assimilate the oligosaccharides. A good example of this is marsupials, the milk of which, unlike bovine milk, is low in lactose and has high levels of oligosaccharides (Green et al. 1987; Messer et al. 1987).

Human milk is also rich in oligosaccharides. However, there is enough evidence available in the scientific literature to suggest that most of the human milk oligosaccharides are not digested or absorbed into the small intestine of infants, and are instead delivered intact into the colon (Brand Miller et al. 1995; McVeagh \& Brand Miller, 1997). It is, therefore, reasonable to assume that oligosaccharides are present in milk for reasons other than nutrition.

\section{Oligosaccharides as prebiotics}

The definition of prebiotics is 'non-digestible food ingredients that beneficially affect the host by selectively stimulating the growth and/or activity of one or a limited number of bacteria in the colon that can improve the host health' (Gibson \& Roberfroid, 1995).

Milk oligosaccharides fit this definition because they are neither digested nor absorbed in the upper intestinal tract of humans but are delivered intact into the colon where they can act as nutrients for colonic microflora. There is evidence that neutral oligosaccharides present in human milk act as growth enhancers for bacteria of the genus Bifidobacterium in infants. Yoshihama et al. (1982) compared the faecal flora of breast-fed infants with that of bottle-fed infants, and showed that levels of bifidobacteria were significantly higher in the former. This study further showed that if the milk of bottle-fed infants was supplemented with 6-galactosyl-lactose, an increase in the faecal population of bifidobacteria was observed. It was postulated that the increased metabolic activity of larger populations of bifidobacteria in the lumen can decrease the intestinal $\mathrm{pH}$, and that this in turn can inhibit proliferation of pathogenic Gram-negative bacteria such as Shigella flexneri and Escherichia coli (Montreuil, 1994). Bovine colostrum is also known to contain galactosyl-lactose together with other neutral oligosaccharides (Saito et al. 1987).

\section{Oligosaccharides as soluble receptors for pathogenic bacteria and viruses}

Oligosaccharides may be viewed as a 'natural' way of protecting neonates against infection. It is possible that they act as competitive inhibitors against important gut pathogens at the intestinal surface. As discussed above, human milk contains more than 80 oligosaccharides and these molecules do not seem to be digested in the small intestine. Milk bathes the gastrointestinal tract of the neonate and the large range of oligosaccharides may provide a means to inhibit pathogen adhesion to the intestinal epithelium.

A large body of evidence is accumulating to support such a hypothesis (e.g. for reviews see Varki, 1993; Zopf \& Roth, 1996; Newburg, 1999). It is believed that oligosaccharides and glycoconjugates in milk and colostrum are soluble receptor analogues of epithelial cell-surface carbohydrates and can therefore compete with virulent bacteria and viruses for attachment sites. Andersson et al. (1986) showed that human milk oligosaccharides inhibited adhesion of pneumococci or influenza virus to pharyngeal or buccal epithelial cells. Similarly, sialylated oligosaccharides were shown to inhibit binding of pathogenic strains of $E$. coli in neonates (Parkkinen et al. 1983; Korhonen et al. 1985). Neutral oligosaccharides from human milk may protect the intestinal tract of neonates from Vibrio cholera (Holmgren et al. 1983). The role of fucosylated oligosaccharides in the interaction of an enterotoxin with cells has also been reported (Brand Miller et al. 1994). More recently Simon et al. (1997) demonstrated that adhesion to epithelial cells by the ulcer-causing human pathogen Helicobacter pylori was inhibited by sialylated oligosaccharides. In this study the binding of thirteen bacterial isolates to epithelial cell-lines was examined and the effect of pretreatment of the bacteria with oligosaccharides, glycoproteins and glycolipids was determined. The most effective inhibitor of binding was found to be 3-sialyl-lactose which had millimolar $50 \%$ inhibitory concentration $\left(\mathrm{IC}_{50}\right)$.

\section{Conclusion}

In summary, it can be concluded that oligosaccharides and glycoconjugates are important bioactive molecules, present not as nutrients for energy but to provide protection in the first few days in the life of a newborn. They may have a role as micronutrients to meet the specific need of rapidly developing infant, e.g. a source of sialic acid which has a role in the development of the nervous system. Levels of oligosaccharides and glycoconjugates are higher in colostrum than mature milk for both humans and bovines, in bovine milk the level of oligosaccharides drops to trace amounts postparturition. In comparision to human milk oligosaccharides which have a large and diverse array of molecules, the composition of bovine milk oligosaccharides is simple. However, structurally bovine oligosaccharides and glycoconjugates are similar to those found in human milk. It is reasonable to assume that the bioactivity of such molecules would also be similar and therefore can be used in milk products with 'functional attributes' for human nutrition.

\section{Acknowledgement}

We thankfully acknowledge Drs Frank Cross and Tim 
Coolbear for critically reading the manuscript and making many useful suggestions.

\section{References}

Andersson B, Porras O, Hanson L, Lagergard T \& SvanborgEden C (1986) Inhibition of attachment of Streptococcus pneumoniae and Haemophilus influenzae by human milk and receptor oligosaccharides. Journal of Infectious Diseases 153, 232-237.

Brand Miller J, McVeagh P \& Bull S (1994) Biological function of oligosaccharides. Acta Paediatrica 83, 1051.

Brand Miller J, McVeagh P, McNeil Y \& Gillard B (1995) Human milk oligosaccharides are not digested and absorbed in the small intestine of young infants. Proceedings of the Nutrition Society of Australia 19, 44.

Carlson SE (1985) $N$-Acetylneuraminic acid concentrations in human milk oligosaccharides and glycoproteins during lactation. American Journal of Clinical Nutrition 41, 720-726.

Cleary T, Chambers J \& Pickering L (1985) Protection of mice from heat stable enterotoxin of $E$. coli by infant formulas. Journal of Pediatric Gastroenteterology Nutrition 4, 125-131.

Gibson G \& Roberfroid M (1995) Dietary modulation of human colonic microbiota-introducing the concept of probiotics. Journal of Nutrition 125, 1401-1412.

Green B, Merchant J \& Newgrain K (1987) Milk composition in the eastern quoll, Dasyurus viverrinus (Marsupialia, Dasyuridae). Australian Journal of Biological Science 40, 379-387.

Holmgren J, Svennerholm A \& Lindbhad M (1983) Receptor like glyco compounds in human milk that inhibit classical and E1 Tor Viberio cholera cell adhesion (haemagglutination). Infection and Immunity 39, 147-154.

Jenness R (1974) The composition of milk. In Lactation: A Comprehensive Treatise, pp. 3-107 [BL Larson and VR Smith, editors]. New York: Academic Press.

Kanamaru Y, Toyoki T, Nagaoka S, Kuzuya Y \& Niki R (1993) High molecular weight mucin-like glycoprotein in bovine milk. Bioscience, Biotechnology and Biochemistry 57, 666-667.

Kobata A (1977) Milk glycoproteins and oligosaccharides. In The Glycoconjugates Vol. I, pp. 423 [M Horowitz and W Pigman, editors]. New York: Academic Press.

Korhonen T, Valtonen M, Parkkinen J, Vaisanen-Rhen V, Finne J, Orskov F, Orskov I, Svenson S \& Makela P (1985) Serotypes, hemolysin production, and receptor recognition of Escherichia coli strains associated with neonatal sepsis and meningitis. Infection and Immunity 48, 486-491.

Kuhn R \& Brossmer R (1956) Ueber o-acetyllactaminsaurelactose aus Kuh-Colostrum und ihre Spaltbarkeit durch Influenza virus. Chemistry Berlin 89, 2013-2025.

Kulkarni PR \& Pimpale NV (1989) Colostrum - a review. Indian Journal of Dairy Science 42, 216-224.

Kunz C \& Rudloff S (1993) Biological functions of oligosaccharides in human milk. Acta Paediatrica 82, 903-912.

Kunz C, Rodriguez-Palmero M, Berthold K \& Jensen R (1999) Nutritional and biochemical properties of human milk, part 1; general aspects, proteins and carbohydrates. Clinics in Perinatology 26, 307-333.

McVeagh P \& Brand Miller J (1997) Human milk oligosaccharides, only the breast. Journal of Paediatric Child Health 33 281-286.

Messer M, Fitzgerald P, Merchant J \& Green B (1987) Changes in milk carbohydrates during lactation in the eastern quoll Dasyurus viverrinus (Marsupialia). Comparative Biochemistry and Physiology B 88, 1083-1086.

Montreuil J (1994) The saga of human milk oligosaccharides. In
New Perspectives in Infant Nutrition, pp. 3-11 [B RennerG Sawatzki, editors]. Thieme: Stuttgart.

Montreuil J \& Mullet S (1960) Etude des variations des constituents glucidiques du lait de femme au cours de la lactation. Bulletin Societé de Chimie Biologique 42, 365-373.

Neeser J-R, Golliard M \& Vedovo SD (1990) Quantitative determination of complex carbohydrates in bovine milk and in milk based infant formulas. Journal of Dairy Science 74, 28602871.

Newberg D (1999) Human milk glycoconjugates that inhibit pathogens. Current Medicinal Chemistry 5, 117-127.

Newberg D \& Neubauer S (1995) Carbohydrates in milks, analysis, quantities, and significance. In Handbook of Milk Composition, pp. 273-349 [RG Jensen, editor]. New York: Academic Press.

Parkkinen J \& Finne J (1985) Occurrence of $N$-acetylglucosamine 6-phosphate in complex carbohydrates. Characterisation of a phosphorylated sialyl oligosaccharide from bovine colostrum. Journal of Biological Chemistry 260, 10971-10975.

Parkkinen J \& Finne J (1987) Isolation of sialyl oligosaccharides and sialyl oligosaccharide phosphates from bovine colostrum and human urine. Methods in Enzymology 138, 289-300.

Parkkinen J, Finne J, Achtman M, Vaisanen V \& Korhonen T (1983) Escherichia coli strains binding neuraminyl alpha 2-3 galactosides. Biochemical and Biophysical Research Communications 111, 456-461.

Polonosky M \& Lespagnol A (1933) Nouvelles acquisitions sur les composes glucidiques du lait de femme. Bulletin of the Society for Chemistry and Biology 15, 320-349.

Saito T, Itoh T \& Adachi S (1984) Presence of two neutral disaccharides containing $\mathrm{N}$-acetylhexosamine in bovine colostrum as free forms. Biochimica et Biophysica Acta 801, 147150 .

Saito T, Itoh T \& Adachi S (1987) Chemical structure of three neutral trisaccharides isolated from bovine colostrum. Carbohydrate Research 165, 43-51.

Sanchez-Diaz A, Ruano M, Lorente F \& Hueso P (1997) A critical analysis of total sialic acid and sialoglycoconjugate content of bovine milk-based infant formulas. Journal of Pediatric Gastroenterology and Nutrition 24, 405-410.

Schneir M \& Rafelson M (1966) Isolation and characterisation of two structural isomers of $\mathrm{N}$-acetylneuraminyl lactose from bovine colostrum. Biochimica et Biophysica Acta 130, 1-11.

Schroten H, Lethen A \& Hanisch R (1992) Inhibition of adhesion of S-fimbriated Escherichia coli to epithelial cells by muconium and faeces of breast-fed and formula-fed newborns. Mucins are the major inhibitory component. Journal of Pediatric Gastroenterology and Nutrition 15, 150-155.

Shimazu M, Yamauchi K, Miyauchi Y, Sakurai T, Tokugawa K \& McIlhinney AJ (1986) High-Mr glycoprotein profiles in human milk serum and fat globular membrane. Biochemical Journal 233, 725-730.

Simon PM, Goodee PL, Mobasseri A \& Zopf D (1997) Inhibition of Helicobacter pylori binding to gastrointestinal epithelial cells by sialic acid-containing oligosaccharides. Infection and Immunity 65, 750-757.

Takamizawa K, Iwamori M, Mutai M \& Nagai Y (1986) Gangliosides of bovine butter milk. Isolation and characterization of a novel monosialoganglioside with a new branching structure. Journal of Biological Chemistry 261, 5625-5631.

Urashima T, Saito T, Ohmisya K \& Shimazaki K (1991) Structural determination of three neutral oligosaccharides in bovine (Holstein-Friesian) colostrum, including novel trisaccharide; GalNAc $\alpha 1-3$ Gal $\beta 1-4$ Glc. Biochimica et Biophysica Acta 1073, 225-229.

Varki A (1993) Biological roles of oligosaccharides; all of the theories are correct. Glycobiology 3, 97-130. 
Veh RW, Michalski J, Corfield AP, Sander-wewer M, Dagmar G \& Schauer R (1981) New chromatographic system for the rapid analysis and preparation of colostrum sialyl oligosaccharides. Journal of Chromatography 212, 313-322.

Yoshihama M, Mochizuki E, Mitsuhashi S \& Ahiko K (1982)

Studies on the application of galactosyl lactose for infant formula. III Effect of galactosyl lactose on intestinal bacterial flora of newborn infants. Yukijinushi Nyugyo Gijyutsu Kenkyushu, Hokoku 78, 33-37.

Zopf D \& Roth S (1996) Oligosaccharides anti-infection agents. Lancet 347, 1017-1021. 